VOL. 169, NO. 1 THE AMERICAN NATURALIST JANUARY 2007

\title{
Uncovering the Biodiversity of Genetic and Reproductive Systems: Time for a More Open Approach
}

\author{
American Society of Naturalists E. O. Wilson Award Winner Address
}

Laurent Keller ${ }^{\dagger}$

Department of Ecology and Evolution, Biophore, University of Lausanne, CH 1015 Lausanne, Switzerland

AвSTRACT: Important scientific findings frequently arise from serendipitous findings. Unfortunately, many scientists are not prepared to take advantage of unexpected results and to question established paradigms, and this prevents them from capitalizing on their good fortune. In this essay, I first explain how pure serendipity led us to discover unusual modes of reproduction such as clonal reproduction by males and a green-beard gene. Next, I argue that the reproductive systems of ants and other organisms are probably much more diverse than is generally appreciated. This leads me to advocate for a new "molecular naturalist" approach to reproductive systems and a more "naturalistic" approach in population and evolutionary genetics. Finally, I make two further points. The first is that our current funding and education systems tend to hinder originality and curiosity. The other is that the field of ecology and evolution, and more generally all of science, would benefit from a shift in values from scientific productivity to scientific creativity. A few suggestions are made to this effect.

Keywords: reproductive systems, molecular naturalist, clonal reproduction, green-beard gene, serendipity, scientific discoveries, creativity.

Le hasard ne favorise que les esprits préparés. (Louis Pasteur [1854])

Creativity is allowing yourself to make mistakes. Art is knowing which ones to keep. (Scott Adams)

* Laurent Keller received the 2005 E. O. Wilson Naturalist Award. The E. O. Wilson Naturalist Award is given to an active investigator in midcareer who has made significant contributions to the knowledge of a particular ecosystem or group of organisms and whose research and writing illuminate principles of evolutionary biology and an enhanced appreciation of natural history.

† E-mail: laurent.keller@unil.ch.

Am. Nat. 2007. Vol. 169, pp. 1-8. (C) 2007 by The University of Chicago. 0003-0147/2007/16901-41957\$15.00. All rights reserved.
Over the past two centuries, there has been a paradigm shift in biology and the sciences in general. In the nineteenth century, scientists would be praised for being good naturalists, Darwin being an excellent example. He spent several years traveling around the world to collect museum samples, an activity that was then valued as true science. Darwin's travels doubtlessly were central to the elaboration of his theory of natural selection. His field notes and museum collections also allowed him to document and support his theory with an exquisite number of examples. Nowadays, it would be hard to imagine funding bodies that would support the type of research conducted by Darwin. To be successful requires one to conduct a hypothesis-driven project with well-defined experiments and predictions. In some countries, funding agencies even require sufficient preliminary data (or even more) to demonstrate that the project is feasible, further decreasing the space left for undertaking new and creative research.

In principle, there is nothing wrong with the hypothesisdriven approach. Indeed, this paradigm has proved extremely successful in ecology and evolution, establishing a framework where experimental studies are integrated with theory. However, a problem with this approach and the current academic system, in my view, is that it castrates the creativity of a great majority of our students and researchers. Here I would like to make the point that interesting scientific findings frequently arise from serendipitous findings and that we are frequently unprepared to profit from unexpected results. To make this point, I shall describe three instances where my colleagues and I have uncovered new and unusual reproductive systems in ants by exploiting such unanticipated results. Next, I will argue that the reproductive systems of ants and other organisms are probably much more diverse than appreciated and that a more "naturalistic" approach in population and evolutionary genetics would prove useful for studying the "biodiversity" of reproductive systems. Finally, I shall make 
a few suggestions about grant proposal assessments, hiring procedures, and teaching philosophy that may help to promote scientific creativity over mere scientific productivity.

\section{Green-Beard Genes and the Genetic Basis of Social Organization in Fire Ants}

My colleague Ken Ross and I uncovered the first example of a green-beard gene (a type of selfish gene), as well as a genetic element influencing social organization, by complete serendipity. After completion of my PhD, I decided to work on the fire ant Solenopsis invicta because this species exhibits two types of social organization, a monogyne form in which colonies have a single queen and a polygyne form where colonies contain a large number of queens. As in many other ants, this difference in queen number is associated with differences in a host of reproductive and social traits, including queen phenotype and breeding strategy, mode of colony reproduction, and pattern of sex allocation (Ross and Keller 1995). My plan was to conduct cross-garden experiments to show that social environment could influence the phenotype of queens and their breeding opportunities.

Together with Ken Ross, I conducted such an experiment, showing that social environment indeed affected the phenotype of queens (Keller and Ross 1993b). However, a population genetic study showed that while the two social forms had similar allele frequencies at most loci studied, they differed in allele frequencies at the enzyme-encoding gene Pgm-3 (Phosphoglucomutase-3; Ross 1992). Moreover, genotypes at this locus strongly departed from HardyWeinberg distribution in the polygyne form. In such cases, the usual procedure in population genetics is to discard misbehaving loci, and most researchers would not investigate further the reasons underlying departure from Hardy-Weinberg. Following this procedure would have led us to conclude that there is no genetic difference between the two social forms and that the differences are culturally transmitted.

But Ross was curious enough to look in more detail at the genotypic data. He noticed that one class of homozygotes $\left(P g m-3^{A A}\right)$ was completely lacking among reproductive queens in polygyne but not monogyne colonies. This prompted us to design experiments to identify the mechanism responsible for this class of homozygous queens never becoming reproductively active in polygyne colonies. We tested several hypotheses, such as Pgm-3 being associated with a dispersal polymorphism. Our experiments disproved all but one of the hypotheses. We found that the genotype at the locus Pgm-3 was strongly associated with the phenotype of queens and their probability of being accepted by workers in established polygyne colonies. The Pgm- $3^{A A}$ queens were selectively de- stroyed by workers when they initiated reproduction in polygyne colonies (Keller and Ross 1993a). Intriguingly, $P g m-3^{A A}$ queens are heavier and more fecund than queens with alternate genotypes, raising the question of why workers selectively destroy them.

The answer was to come several years later, after another serendipitous finding. Again using genetic markers for a population genetic study, Ross found evidence for selection at another locus. In the monogyne form, all queens were found to be homozygous for the allele $B$ at the locus $G p$ 9 (general protein-9), while almost all reproductive queens had a heterozygote $G p-9^{B b}$ genotype in the polygyne form. The allele $G p-9^{b}$ was found to be a recessive deleterious allele, with many $G p-9^{b b}$ females dying prematurely as adults (Ross 1997). Moreover, there is almost no recombination between $G p-9$ and $P g m-3$, and all the known phenotypic and behavioral effects associated with $G p-9$ and $P g m-3$ can be accounted for by the effect of a single locus (Gp-9) or one or several completely linked genes (Keller and Ross 1999). Experimental studies also unraveled why polygyne colonies host only $G p-9^{B b}$ queens. $G p-9^{b}$ (or allelic variants at one or several loci completely linked to the allele $G p-9^{b}$ ) behaves as a green-beard gene that induces workers carrying one copy of that allele to selectively kill queens lacking one copy of that allele (Keller and Ross 1998).

In addition to its selfish property, $G p-9$ also determines the existence of the monogyne and polygyne social forms (Ross and Keller 1998). Monogyne colonies are always headed by $G p-9^{B B}$ queens mated with $G p-9^{B}$ males, and the $G p-9^{B B}$ workers in such colonies never accept additional queens (regardless of their $G p-9$ genotype). However, when the proportion of $G p-9^{B b}$ workers is greater than $15 \%$ (which is always true in polygyne colonies), workers readily accept several queens but only those carrying at least one copy of the $G p-9^{b}$ allele (Ross and Keller 2002). Hence, social organization in the fire ant depends on whether or not colonies contain a given proportion of $G p-9^{B b}$ workers.

The locus Gp-9 has now been cloned, and its putative function is consistent with the gene being directly involved in the selective killing of $G p-9^{B B}$ queens by workers. It was previously shown that workers discriminate between queens on the basis of their odor (Ross and Keller 1998), and $G p-9$ encodes odorant-binding proteins that have been shown in some cases to be involved in chemical recognition in insects (Krieger and Ross 2002).

\section{Conditional Use of Sex in Cataglyphis cursor}

While conducting his $\mathrm{PhD}$ research under the supervision of Serge Aron, Morgan Pearcy was using four microsatellites to study the breeding structure and sex ratio in 
the ant Cataglyphis cursor. Pearcy's interest in this ant stemmed from the fact that new colonies are formed in a very unusual manner. In ants, queens generally disperse during a mating flight and thereafter start a new colony on their own. But, in a manner similar to that of the honeybee, young C. cursor queens return to their parental nest after mating in the vicinity rather than dispersing. To study the breeding structure of this species, Pearcy analyzed genotypes of queens and workers within colonies and realized that they consistently had different genotypes. Further analyses were to show that new queens were produced by parthenogenesis, while workers were produced by normal sexual reproduction. This prompted us to collect more colonies to determine the proportion of queens and workers produced by parthenogenesis and sexual reproduction. The analysis of 35 colonies revealed that $96 \%$ of the queens were produced by parthenogenesis (Pearcy et al. 2004). By contrast, only $2.5 \%$ of the workers were produced by parthenogenesis. Thus, queens of this species use alternate modes of reproduction to produce queens and workers, a strategy completely unknown in social insects.

The use of both sexual and asexual reproduction allows C. cursor queens to maximize their reproductive success by increasing the transmission rate of their genes to their reproductive female offspring while maintaining genetic diversity in the worker force. Indeed, it is thought that reduced genetic diversity in the worker force may be detrimental for the colony because it leads to reduced defense against parasites (Sherman et al. 1988), less efficient division of labor, and a decreased range of environmental conditions that a colony can tolerate (Crozier and Page 1985; Cole and Wiernasz 1999). These costs are akin to those thought to lead to the instability of parthenogenetic reproduction in nonsocial organisms (Maynard Smith 1979). In other words, C. cursor queens take advantage of the social caste system to use sex for somatic growth and parthenogenesis for germ line production.

Again, this surprising finding arose by pure serendipity, and the differential mode of production of queens and workers would not have been uncovered in this ant had Pearcy not carefully compared the genotypes of individuals within colonies.

\section{Clonal Reproduction by Males and Queens in the Little Fire Ant}

A few years ago, Arnaud Estoup, Denis Fournier, Jérome Orivel, and I started a population genetic study on Wasmania auropunctata. This tramp species has been introduced from Neotropical lowland forests to many islands, where it has become a major pest. The project was to determine whether the introduction into new habitats could have been associated with decreased genetic diversity and possibly a shift in social organization, as had been suggested for some other ants (Tsutsui et al. 2000; Giraud et al. 2002; Pedersen et al. 2005). To conduct the proposed studies, Estoup and his colleagues developed 12 microsatellites. Next, Estoup went with Fournier and Orivel to French Guyana to collect nests from five sites. An analysis of workers, queens, and the sperm in their spermathecae revealed an unusual pattern, with males having genotypes different from those of queens and workers. Even more striking was that queens collected from different nests of a given site almost invariably had sperm with identical genotypes at all 12 microsatellites. While discussing these data on the phone, Estoup suggested that one possible explanation for this pattern was a single male per site fertilizing all the queens. Unfortunately, the sex life of ant males is generally much less glamorous, as they typically have degenerated testes and are eaten immediately after their mating flight by the female workers.

Upon careful examination of the genotypes within nests, we uncovered a very unusual mode of reproduction (Fournier et al. 2005). Similar to Cataglyphis cursor, queens are produced asexually and workers sexually. However, there is a complete specialization of the mode of reproduction for each caste in the case of the little fire ant. An additional difference is that there seems to be no recombination during asexual reproduction in $W$. auropunctata; hence, new queens are produced clonally. While allowing queens to maximize their rate of transmission of their genes, this mode of reproduction also has strong fitness consequences for males because they never father queens. In fact, males might even have zero reproductive success because ant males normally develop from unfertilized maternal eggs (because of the haplodiploid Hymenoptera sex determination system) and because W. auropunctata's workers are completely sterile.

But our offspring analyses were to reveal another twist to the story. All males had the same genotypes as their fathers. They were clonally produced as well. A plausible mechanism underlying this mode of reproduction is elimination of the maternal genome in the egg. Accordingly, the resulting haploid males would lack maternal genes and would have a genotype identical to the sperm stored in the queens' spermathecae. In the evolutionary battle between the sexes, $W$. auropunctata has thus evolved an unusual mode of reproduction, with queens circumventing the twofold cost of sexual reproduction by transferring all their genes to the reproductive females, while males thwart queens by also clonally transmitting their genomes to sons. Although the male and female genomes come together in workers, this does not translate into any genetic exchange because workers are completely sterile. As a result, the male 
and female genomes are completely segregated and form two distinct genetic lineages within the species.

Again, this unusual system of reproduction was discovered by complete serendipity while conducting a population genetic study of an invasive ant.

\section{Allozymes and Microsatellites as Tools to Uncover the Biodiversity of Genetic and Reproductive Systems in Ants and Other Organisms}

Microsatellites have become a common tool in population genetic studies, conservation biology, paternity analyses, and the study of plant and animal breeding systems. Interestingly, in a sizable proportion of these studies, one or several microsatellites yield genotypes that do not follow a Hardy-Weinberg distribution. Typically, it is suggested in the paper's "Material and Methods" section that this pattern probably stems from null alleles. Accordingly, the focal microsatellites are discarded, and no further effort is made to understand why genotypes have strange distributions or why allele frequencies differ between sexes or samples. This is a pity, because in many cases the observed pattern might stem from non-Mendelian inheritance of the markers or selection acting on genes linked to these markers. I even suspect that unusual results remain unreported because they cannot be readily explained and/or do not fit the established paradigm. This is why I sometimes ask colleagues whether they are aware of strange genetic data. Recently, in Regensburg, my colleague Jurgen Heinze told me that his collaborator Kyohsuke Ohkawara might have such data for the ant Vollenhovia emryi. I contacted Ohkawara, who told me that he indeed had difficulties interpreting the genotypes obtained. He kindly sent me a manuscript reporting important differences in allele frequencies between queens, workers, and males, as well as males having alleles absent in queens. He proposed several scenarios to account for these data, including an effect of the genes on caste determination and chromosome fusion. I told him that I might have a possible explanation, and he kindly sent me the data. The genotypes indicated that $V$. emryi most likely has the very same mode of reproduction as Wasmania auropunctata, with clonal reproduction by both queens and males (Ohkawara et al. 2006), hence explaining why the genotypes within colonies were so strange.

Two other discoveries of unusual modes of reproduction indicate that ant reproductive systems might be more variable than is generally recognized. It is generally accepted that the distinct developmental pathways of queens and workers are induced only by environmental and social factors. However, exceptions to such environmentally determined caste differentiation have now been found in several populations of Pogonomyrmex harvester ants
(Helms Cahan et al. 2002; Julian et al. 2002; Volny and Gordon 2002). In each case, a given population comprises two genetically distinct lineages (Helms Cahan and Keller 2003), and queens (which can be of either lineage) mate with males of both lineages (Schwander et al. 2007). Purelineage female offspring develop into queens, while interlineage females almost invariably develop into workers. This mode of caste determination is genetically hardwired, because females mated exclusively to males of their own lineage largely fail to produce workers and cannot successfully found new colonies. The lineages with genetic caste determination most likely arose from historical hybridization between the species Pogonomyrmex rugosus and Pogonomyrmex barbatus, which have typical environmental systems of caste determination (Helms Cahan and Keller 2003).

Another similar case of genetic differences across female castes associated with interspecific hybridization has also been demonstrated by Sara Cahan Helms (Helms Cahan and Vinson 2003) in the genus Solenopsis. In Solenopsis xyloni, colonies contain several queens, each mated with a single male. In areas of sympatry with Solenopsis geminata, microsatellite analyses revealed that $S$. xyloni colonies contained queens that mated with either a conspecific male or a S. geminata male. The type of mating has a strong influence on the fate of female offspring. Queens mated with a conspecific male produce only new queens, whereas queens mated to a $S$. geminata male produce only workers.

These examples show that, contrary to the generally accepted dogma, there is much variability in the reproductive systems of ants. Undoubtedly, more such examples will be discovered soon, and the challenge will be to determine how common and how diverse are situations departing from the standard view of social Hymenoptera males developing from unfertilized eggs and females developing from diploid eggs, with caste determination depending only on social and environmental factors. Similarly, I would not be surprised if the biodiversity of reproductive systems is higher than realized in other taxa. Indeed, there are an increasing number of examples of non-Mendelian transmission of genomes (Burt and Trivers 2006) and alternative genetic systems in bacteria (Tobiason and Seifert 2006), fungi (Hijri and Sanders 2005), insects (Normark 2003), plants (Gernand et al. 2005), and vertebrates (Hubbs and Hubbs 1932; Stöck et al. 2002). In many cases, these systems evolved because of selfish elements. For example, a selfish gene was uncovered in the flour beetle Tribolium castaneum after mating experiments between individuals from separate populations (Beeman and Denell 1992). This gene, named Medea (maternal effect dominant embryonic arrest), has many of the same properties as Gp-9. When a mother carries Medea, any of her offspring that lack the gene will die early during de- 
velopment. Medea is thus a type of selfish gene that increases its own frequency in a population to the detriment of the organism carrying it. Such selfish genes are probably very common, but they are likely to remain undetected because they are expected to go quickly to fixation.

The side-blotched lizard Uta stanburiana provides another nice example of a weird system of reproduction. Previous work had shown that six color morphs that differ in several behavioral traits coexist in the same population (Sinervo and Clobert 2003). In a recent study, Sinervo et al. (2006) found that several microsatellites cosegregate on the same linkage group. Moreover, most of the microsatellites studied are also associated with known morphological and behavioral differences. Sinervo et al. (2006) interpret these associations as stemming from a green-beard effect, with individuals interacting nonrandomly in the population. However, it remains to be investigated whether such a mechanism may really lead to such a high cosegregation among microsatellites and their strong association with morphological and behavioral differences. I would not be surprised if this system also turns out to originate from hybridization between species, perhaps in a manner similar to that which led to distinct interbreeding genetic lineages in Pogonomyrmex populations.

\section{Toward a More Open Attitude toward Unexpected Results}

The three ant examples taken from our own research were chosen to illustrate the discoveries of unusual modes of reproduction made by pure serendipity while using genetic markers for other purposes. Undoubtedly, we were lucky in finding such systems. But I believe that the probability of such good fortune is high over an entire scientific career. The important challenge is to be able to exploit unexpected results, and therein lies the problem. Currently, scientists have become too specialized and blind to potentially important findings if these do not fit their line of inquiry. An example of this comes from the recent discovery of a new mechanism of inheritance of characters in Arabidopsis. Lolle et al. (2005) found that plants homozygous for recessive mutant alleles of the so-called organ fusion gene HOTHEAD can inherit allele-specific DNA sequence information that was not present in the chromosomal genome of their parents but was present in previous generations. Thus, several independent mutant strains reverted to normal progeny after a few generations because of precise restoration of the original DNA sequence. (The exact mechanisms underlying this mechanism of unorthodox inheritance are not yet identified.) Importantly, with regard to our understanding of the origin of important discoveries, several scientists had previously made similar observations on other Arabidopsis mutant lines.
However, they failed to make sense of their findings, attributing their observation to incomplete penetrance of the mutation they were studying.

There are numerous other examples in the history of science where important findings were serendipitous, made, for example, by scientists obtaining strange data after having committed errors in following standard laboratory protocols (Friedel 2001; Ginger 2005). But these led to discoveries because these scientists did not discard the unexpected data. Rather, they were sufficiently curious to inquire about the causes responsible and to question the generality of an established paradigm. Unfortunately, our current funding and education systems tend to hinder originality and curiosity. Perhaps it is time to change this.

\section{Changing Funding Rules}

A first important factor selecting against curiosity and originality is our funding system. A good grant proposal is one where you can clearly outline the experiments to be done, make predictions, and detail the expected results. Such a proposal allows reviewers to tick the appropriate box when reaching the question "Is the project feasible?" In many countries, grant proposals are also mainly evaluated based on the experiments proposed rather than on the scientific accomplishment of the applicant(s). Unfortunately, there are some excellent scientists who are poor grant writers and, conversely, some rather mediocre scientists who excel in writing grant proposals. The outcome is a suboptimal correlation between the funding rate and scientific achievements. To give a simple example, imagine a grant by W. D. Hamilton being reviewed by a funding agency such as the U.S. National Science Foundation. The probability of funding would be similar to the probability of finding a useful molecule in a homeopathic medicine. Yet Hamilton is a scientist who made some of the most important contributions to the fields of ecology and evolution since Darwin.

I believe that the best predictor of the quality of science that a given scientist will produce in the near future is the quality of the scientific work accomplished during the preceding few years. I have rarely seen a colleague who continually does excellent science suddenly produce uninteresting work, and conversely, there are few people producing dull science who suddenly move into exciting research. Thus, I believe that much more value should be put on previous achievements than on the proposed work when evaluating grant proposals. For this very reason, I usually do not carefully scrutinize grant proposals by scientists whom I hold in high esteem. If they conducted good work over the past few years, then they will almost certainly continue to do so and thus deserve being funded. In that respect, I would thus suggest that reviewers be 
asked about the originality and creative elements of the work described in a grant application rather than whether the project is feasible.

\section{Valuing Originality over Productivity in Hiring Committees}

A problem with most academic hiring committees is that it is productivity rather than originality that is valued. Candidates are frequently compared on the basis of the number of articles published, and the originality and importance of the science are only rarely discussed by committee members. As a result, young scientists are (correctly) told that they should publish many articles in good journals if they want to obtain an academic position. The result is that it pushes one to value quantity over quality: better 20 papers with little content in top journals than two papers reporting important results.

Hamilton again provides a good example to illustrate the current problem with hiring in universities. As Hamilton (1995) explains in exquisite detail in Narrow Roads of Gene Land, volume 1, he did not easily find a job in academia. Imagine young Hamilton now applying for an assistant professor position. He would almost certainly not be short-listed among the 200 or so applications received. And if he were, the committee would almost certainly conclude that his talk was poorly structured and that he would be a bad teacher in the classroom. In the United States, the committee would also correctly conclude that the candidate might have problems getting external funding, another good reason to discard him. On the other hand, there would probably be many candidates with abilities to secure funding, give a perfect seminar, and express a convincing teaching "philosophy." But many of them would also probably be blind to important unorthodox findings. I believe that the situation could be improved if hiring committees would specifically consider whether candidates have contributed something original and important in their fields.

\section{Changing Our Teaching Practices}

Scientific curiosity could also be enhanced by changing our teaching philosophy. Teaching assessment forms show that many students value the teacher's ability to give a well-structured course. In other words, the program should be clearly outlined, and each topic should be given a simple treatment. Incidentally, it is also more comforting for teachers to simplify complex problems and present the material as if knowledge were carved in stone. But the reality is that many of the "facts" that we were taught 20 years ago are now known to be wrong or only partly correct. Thus, I like the way my colleague Ueli Schibler, from the University of Geneva, initiates his lecture course to third-year undergraduate students. Citing Lawrence Shaffer, a distinguished professor of psychology, he informs them that he has two pieces of bad news to start with. The first is that half of what he is going to teach them is wrong, and the second is that he does not even know which half. This warning is particularly telling because Ueli is a molecular biologist, a field where professors tend to be particularly confident about the truth of the processes they are teaching. However, molecular biologists are currently realizing that things are far more complex than they ever imagined. About 20 years ago, it would take a few hours to explain to undergraduates what a gene is and how it works. Now it has become difficult to even define what a gene is (Pearson 2006), and new mechanisms of transfer of information across generations are regularly discovered.

Unfortunately, the problem with teaching philosophy starts much earlier than at the university. There is high emphasis on learning facts by heart, and very little effort is being made to develop the critical abilities of students at all levels in school. An entertaining and useful exercise consists in determining the amount of silliness that one can say in classes until students react. A few years ago, I taught a field course to students preparing to become high school teachers. When I told them really ridiculous things about the behavior of some insects, I was really surprised to see no reaction. Should I have said similar stupidities to my 10-year-old children and their friends, they would have laughed at me and said that I was crazy. But the 20year-old students even underlined in red my stupid statements when I asked them to do so. Clearly, they had been too long in an environment where they had been prevented from thinking - and they were to become teachers of young children the following year.

\section{Conclusion}

I have tried to make two points in this essay. The first is that ants and probably many other organisms have systems of reproduction much more diverse than we generally realize. Uncovering this diversity will prove a big challenge. Molecular markers such as microsatellites offer a unique opportunity. However, we need to be prepared for such discoveries and to be more inquisitive about markers that yield genotypes departing from Hardy-Weinberg distribution. In other words, I advocate a new "molecular naturalist" approach to reproductive systems.

The second point is that the field of ecology and evolution, and more generally all of science, would benefit from a shift in values from scientific productivity to scientific originality. This could be done by changing our education philosophy and teaching students to be more 
critical toward the information we provide them (including the material given in our own classes). When hiring a colleague, one should really try to look not only at the publication record (or other metrics) but also at whether the candidate has really discovered something original. And if it is true that departments cannot run well if they are composed only of original scientists such as Hamilton, there can be little doubt that every department would benefit from accommodating at least a few of them. Finally, it would be good if funding agencies would also put more emphasis on what scientists have really contributed to science rather than what they promise to contribute.

\section{Acknowledgments}

I thank M. Chapuisat, P. Christe, A. Estoup, D. Fournier, R. Hammond, M. Pearcy, K. Ross, U. Schibler, and two anonymous reviewers for comments on the manuscript and the Swiss National Science Foundation for continuous financial support of my work.

\section{Literature Cited}

Beeman, R. W. F. K. S., and R. E. Denell. 1992. Maternal-effect selfish genes in flour beetles. Science 256:89-92.

Burt, A., and R. Trivers. 2006. Genes in conflict: the biology of selfish genetic elements. Harvard University Press, Cambridge, MA.

Cole, B. J., and D. C. Wiernasz. 1999. The selective advantage of low relatedness. Science 285:891-893.

Crozier, R. H., and R. E. Page. 1985. On being the right size: male contributions and multiple mating in social Hymenoptera. Behavioral Ecology and Sociobiology 18:105-115.

Fournier, D., A. Estoup, J. Orivel, J. Foucaud, H. Jourdan, J. L. Breton, and L. Keller. 2005. Clonal reproduction by males and females in the little fire ant. Nature 435:1230-1234.

Friedel, R. 2001. Serendipity is no accident. Kenyon Review 23:3647.

Gernand, D., T. Rutten, A. Varshney, M. Rubtsova, S. Prodanovic, C. Brüss, J. Kumlehn, F. Matzk, and A. Houben. 2005. Uniparental chromosome elimination at mitosis and interphase in wheat and pearl millet crosses involves micronucleus formation, progressive heterochromatinization, and DNA fragmentation. Plant Cell 17: 2431-2438.

Ginger, S. 2005. Minds behind the brain: a history of the pioneers and their discoveries. Oxford University Press, Oxford.

Giraud, T., J. S. Pedersen, and L. Keller. 2002. Evolution of supercolonies: the Argentine ants of southern Europe. Proceedings of the National Academy of Sciences of the USA 99:6075-6079.

Hamilton, W. D. 1995. Narrow roads of gene land. Vol. 1. Evolution of social behaviour. Freeman \& Macmillan, New York.

Helms Cahan, S., and L. Keller. 2003. Complex hybrid origin of genetic caste determination in harvester ants. Nature 424:306-309.

Helms Cahan, S., and B. S. Vinson. 2003. Reproductive division of labor between hybrid and nonhybrid offspring in a fire ant hybrid zone. Evolution 57:1562-1570.

Helms Cahan, S. H., J. D. Parker, S. W. Rissing, R. A. Johnson, T. S. Polony, M. D. Weiser, and D. R. Smith. 2002. Extreme genetic differences between queens and workers in hybridizing Pogono- myrmex harvester ants. Proceedings of the Royal Society B: Biological Sciences 269:1871-1877.

Hijri, M., and I. R. Sanders. 2005. Low gene copy number shows that arbuscular mycorrhizal fungi inherit genetically different nuclei. Nature 433:160-163.

Hubbs, C. L., and L. C. Hubbs. 1932. Apparent parthenogenesis in nature in a form of fish of hybrid origin. Science 76:628-630.

Julian, G. E., J. H. Fewell, J. Gadau, R. A. Johnson, and D. Larrabee. 2002. Genetic determination of the queen caste in an ant hybrid zone. Proceedings of the National Academy of Sciences of the USA 99:8157-8160.

Keller, L., and K. G. Ross. 1993a. Phenotypic basis of reproductive success in a social insect: genetic and social determinants. Science 260:1107-1110.

1993b. Phenotypic plasticity and "cultural transmission" of alternative social organizations in the fire ant Solenopsis invicta. Behavioral Ecology and Sociobiology 33:121-129.

. 1998. Selfish genes: a green beard in the red fire ant. Nature 394:573-575.

1999. Major gene effects on phenotype and fitness: the relative roles of $P g m-3$ and Gp-9 in introduced populations of the fire ant Solenopsis invicta. Journal of Evolutionary Biology 12:672-680.

Krieger, M. J. B., and K. G. Ross. 2002. Identification of a major gene regulating complex social behavior. Science 295:328-332.

Lolle, S. J., J. L. Victor, J. M. Young, and R. E. Pruitt. 2005. Genomewide non-mendelian inheritance of extra-genomic information in Arabidopsis. Nature 434:505-509.

Maynard Smith, J. 1979. The evolution of sex. Cambridge University Press, Cambridge.

Normark, B. B. 2003. The evolution of alternative genetic systems in insects. Annual Review of Entomology 48:397-423.

Ohkawara, K., M. Nakayama, A. Sato, A. Trindl, and J. Heinze. 2006. Clonal reproduction and genetic caste differences in a queen-polymorphic ant, Vollenhovia emeryi. Biology Letters 2:359-363.

Pearcy, M., S. Aron, C. Doums, and L. Keller. 2004. Conditional use of sex and parthenogenesis for worker and queen production in ants. Science 306:1780-1783.

Pearson, H. 2006. What is a gene? Nature 441:398-401.

Pedersen, J. S., M. J. B. Krieger, V. Vogel, T. Giraud, and L. Keller. 2005. Native supercolonies of unrelated individuals in the invasive Argentine ant. Evolution 60:782-791.

Ross, K. G. 1992. Strong selection on a gene that influences reproductive competition in a social insect. Nature 355:347-349.

- 1997. Multilocus evolution in fire ants: effects of selection, gene flow and recombination. Genetics 145:961-974.

Ross, K. G., and L. Keller. 1995. Ecology and evolution of social organization: insights from fire ants and other highly eusocial insects. Annual Review of Ecology and Systematics 26:631-656.

. 1998. Genetic control of social organization in an ant. Proceedings of the National Academy of Sciences of the USA 95: 14232-14237.

- 2002. Experimental conversion of colony social organization by manipulation of worker genotype composition in fire ants (Solenopsis invicta). Behavioral Ecology and Sociobiology 51:287-295.

Schwander, T., S. Helms Cahan, and L. Keller. 2007. Characterization and distribution of Pogonomyrmex harvester ant lineages with genetic caste determination. Molecular Ecology. doi: 10.1111/j.1365294X.2006.03124.x. 
Sherman, P. W., T. D. Seeley, and H. K. Reeve. 1988. Parasites, pathogens, and polyandry in social Hymenoptera. American Naturalist 131:602-610.

Sinervo, B., and J. Clobert. 2003. Morphs, dispersal behavior, genetic similarity, and the evolution of cooperation. Science 300:19491951.

Sinervo, B., A. Chaine, J. Clobert, R. Calsbeek, L. Hazard, L. Lancaster, A. G. McAdam, S. Alonzo, G. Corrigan, and M. E. Hochberg. 2006. Self-recognition, color signals, and cycles of greenbeard mutualism and altruism. Proceedings of the National Academy of Sciences of the USA 103:7372-7377.

Stöck, M., D. K. Lamatsch, C. Steinlein, J. T. Epplen, W. R. Grosse,
R. Hock, T. Klapperstück, et al. 2002. A bisexually reproducing all-triploid vertebrate. Nature Genetics 30:325-328.

Tobiason, D. M., and H. S. Seifert. 2006. The obligate human pathogen, Neisseria gonorrhoeae, is polyploid. Public Library of Science (PLoS) Biology 4:1069-1078.

Tsutsui, N. D., A. V. Suarez, D. A. Holway, and T. J. Case. 2000. Reduced genetic variation and the success of an invasive species. Proceedings of the National Academy of Sciences of the USA 97: $5948-5953$.

Volny, V. P., and D. M. Gordon. 2002. Genetic basis for queen-worker dimorphism in a social insect. Proceedings of the National Academy of Sciences of the USA 99:6108-6111. 